\title{
INTRANEURAL LIPOMA OF THE MEDIAN NERVE IN THE CARPAL TUNNEL
}

\author{
Report of a Case
}

\section{Air Vice-Marshal George H. Morley, Royal Air Force}

A woman of thirty-seven had a swelling in the palm of her left hand which had increased in size for four years. It had always been painless but recently had caused discomfort when holding knitting needles.

On examination, there was a discrete, firm swelling of the left palm which was not tender, but pressure on it caused tingling in the fingers (Fig. 1). There was no restriction of joint movements and no impairment of sensation; power was normal and gripping did not cause symptoms.

Operation-The skin was incised in the line of the thenar crease. The tumour was yellow in colour and was under tension when the palmar fascia was incised. Full exposure was not obtained until the distal half of the flexor retinaculum had been divided. The tumour was then seen to originate from the median nerve a quarter of an inch above the distal border of the retinaculum. Dissection revealed nerve fibres spread out over the surface of the tumour. The motor branch had been displaced distally and was so expanded that it appeared to be a

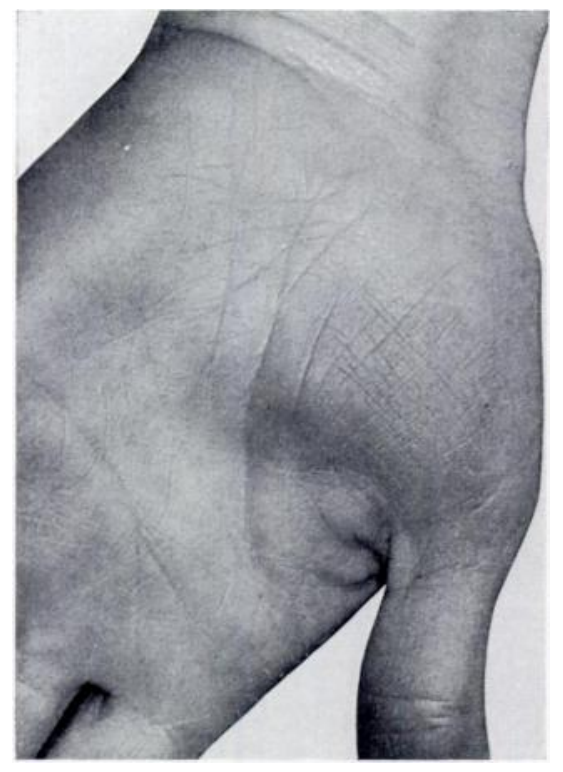

Fig. 1

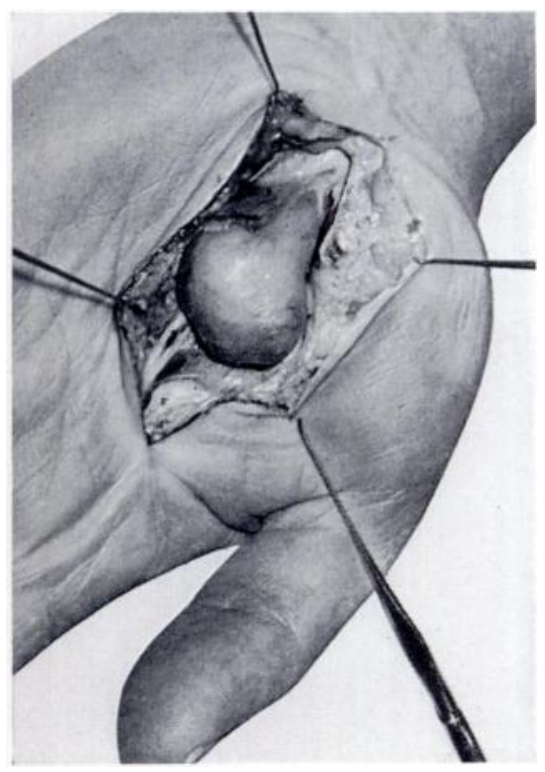

FIG. 2

Figure 1-Before operation. The swelling in the palm gave little indication of the size of the tumour. Figure 2--The tumour exposed at operation.

strand of connective tissue. Further dissection revealed a yellow, pear-shaped, intraneural tumour about 4 by 2.5 centimetres in size within the median nerve (Fig. 2). The nerve fibres were intimately associated with the capsule of the tumour and, even with the greatest care, some damage appeared inevitable in separating them. The tumour was then dissected free from its origin in the median nerve and the rest of the retinaculum was divided (Fig. 3). 
After operation there was some neuralgic pain and numbness of the medial side of the index finger and the lateral side of the ring finger and the scar line was tender. Digital movement was almost full after two weeks. Three months later motor function and power were normal but the numbness persisted, and two months after this the sensation in the ring finger had improved and the index finger was hyperaesthetic. The range and power of movement were

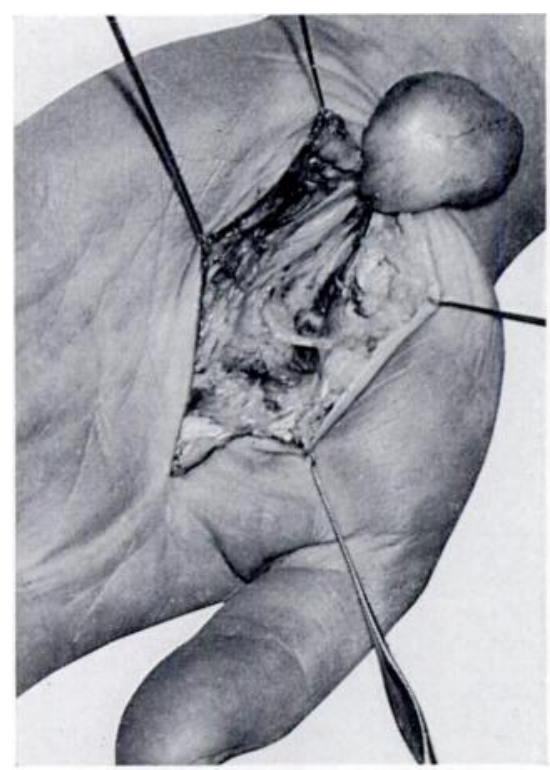

FIG. 3

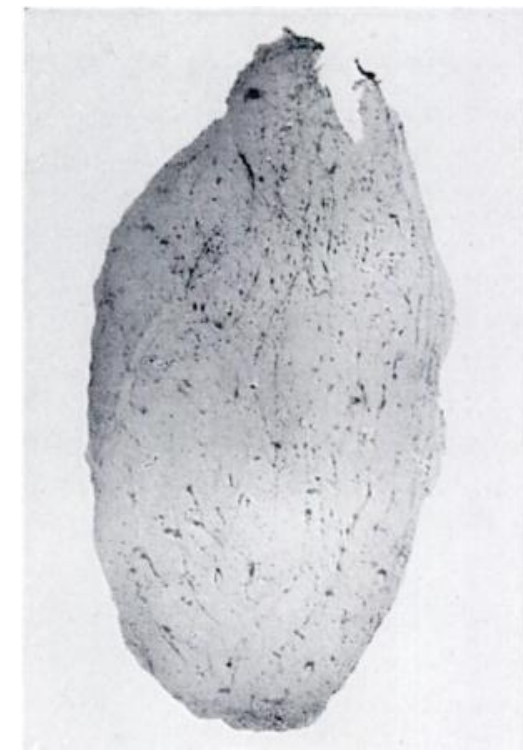

FIG. 4

Figure 3-Showing reflection of the tumour before excision and the expanding fibres of the median nerve. Figure 4-Low-power photomicrograph of the specimen. The lesion can be seen as a discrete non-lobated mass of fatty tissue with very scant fibrous supporting stroma, through which blood vessels course. No nerve elements are found entrapped within the lipoma. (Haematoxylin and eosin, $\times 1 \cdot 75$.)

normal and the scar and operation area were not tender, nor was there any bowstringing of the flexor tendons.

Pathological examination (Group Captain R. M. Cross, D.C.P.)-The specimen consisted of a rounded mass of yellow fatty tissue 2 centimetres across enclosed in a thin fibrous capsule. On microscopic examination, sections showed adipose tissue and an irregularly scattered stroma of fibrous tissue. No neural elements could be demonstrated and the tumour was identified as a benign lipoma.

I am indebted to Air Marshal Sir Richard Nelson, Director General of Medical Services, Ministry of Defence (R.A.F.), for permission to publish this case report. 